\title{
Implementasi Metode Path Finding dengan Penerapan Algoritma A-Star untuk Mencari Jalur Terpendek pada Game "Jumrah Launch Story"
}

\author{
Ghani Mutaqin ${ }^{1}$, Juniardi Nur Fadilah ${ }^{2}$, Fresy Nugroho ${ }^{3}$ \\ 1,2,3 Teknik Informatika, Fakultas Sains dan Teknologi, Universitas Islam Negeri Maulana \\ Malik Ibrahim Malang \\ 18650009@student.uin-malang.ac.id ${ }^{1}$, juniardi.nur@gmail.com² ${ }^{2}$, fresysss@gmail.com³
}

\begin{abstract}
Technology is increasingly developing from time to time as it is today, especially the development of game technology. Develop in-game technology so that the game can be like in the real world. To make a realistic game, of course, implement artificial intelligence or artificial intelligence in the behavior of NPCs (non-player characters) / intelligent agents in games. One of the common behaviors we know about smart agents in games is pathfinding. Pathfinding is one of the basic concepts of algorithms used to move characters in the game. By using the pathfinding method, intelligent agents can move intelligently like the real world. This is what makes the game even more interesting. However, the problem is how the intelligent agent in the game can find the shortest path of the route to be traversed efficiently. In this study, we applied the A-Star algorithm through the pathfinding method of NPC behavior in games. As the results of this research, we made a game entitled "Jumrah Launch Story".
\end{abstract}

Key words: Game, pathfinding, A-Star, Intelligence

Abstrak

Teknologi semakin berkembang dari waktu ke waktu seperti saat ini, khususnya perkembangan teknologi game. Pengembangkan teknologi dalam game agar game bisa menjadi seperti layaknya di dunia nyata. Untuk membuat game yang realistis tentunya mengimplementasikan artificial intelligence atau kecerdasan buatan pada perilaku NPC (non player character) / agen cerdas dalam game. Salah satu perilaku yang umum kita ketahui pada agen cerdas dalam game adalah path finding. Path finding merupakan salah satu konsep dasar algoritma yang digunakan untuk menggerakkan karakter dalam game. Dengan menggunakan metode path finding, agen cerdas bisa bergerak dengan cerdas layaknya dunia nyata. Hal ini lah yang membuat game bisa menjadi menjadi lebih menarik. Namun yang menjadi masalah adalah bagaimana agen cerdas dalam game bisa mencari jalur terpendek dari rute yang akan dilalui yang efisien. Pada penelitian ini kami menerapkan algoritma A-Star melalui metode path finding pada perilaku NPC didalam game. Hasil dari penelitian ini kami membuat game yang berjudul "Jumrah Launch Story".

Key words: Game, path finding, A-Star, NPC, Kecerdasan

http://journal.walisongo.ac.id/index.php/jit/index

WJIT : Walisongo Journal of Information Technology

WJIT : Walisongo Journal of Information Technology - Vol.3 No. 1 (2021) 


\section{PENDAHULUAN}

Teknologi semakin berkembang dari waktu ke waktu, khususnya teknologi Game. Industri game adalah salah satu usaha pengembangan industry kreatif. Kemajuan grafis dalam perkembangan game membuat lingkungan game dan jalannya permainan tampak lebih realistis(Theosaksomo, 2017). Namun untuk membuat sebuah game tampak nyata, grafis saja tidak ukup jika tidak didukung dengan penerapan perilaku cerdas pada NPC (Non Player Character)(Harsadi \& Siswanti, 2019). Untuk memberikan kecerdasan pada game diperlukan penerapan Artificiall Intelligence.

Salah satu metode yang banyak kita ketahui dalam kecerdasan game adalah path finding. Path finding ialah konsep yang digunakan untuk menggerakkan karakter dalam permainan. Metode ini biasanya digunakan sebagai initi pergerakan AI(Rahadiansyah et al., 2016). Dengan algoritma ini, karakter dalam game dapat bergerak seperti perilaku manusia di dunia nyata. AI ialah kecerdasan buatan yang didesain kedalam suatu sistem untuk mensimulasikan kecerdasan manusia dan menyelesaikan permasalahan dengan menggunakan computer seperti di dunia nyata(Wijaya et al., 2017). Banyak hal yang dapat diamati dari perilaku kecerdasan dalam game. Agar NPC sebagai pelaku kecerdasan dapat bergerak senatural mungkin. Pada game ini penulis menggunakan algoritma A-Star sebagai algoritma path finding yang akan diterapkan pada kecerdasan karakter pada game yang berjudul "Jumrah Launch Story".

\section{METODE}

Metode dari penelitian ini adalah menggunakan algoritma $A$-Star. Untuk menguji ketepatan algoritma ini penulis menggunakan model dasar agar metode yang digunakan dapat berjalan maksimal. Metodologi ini digunakan dengan menitik-beratkan pada aspek desain, fungsi, dan User Interface(Prasetyo et al., 2017). Sistem ini digunakan untuk mengembangkan secara sederhana dari sistem yang akan diteliti untuk evaluasi dan perbaikan(Verma et al., 2015). Tahapan yang akan dilakukan dalam penelitian ini terdiri dari analisa, studi literatur, dan perancangan aplikasi game.

Analisa digunakan untuk melihat apa saja yang dibutuhkan dalam proses pembuatan game ini. Analisa difokuskan pada NPC di dalam permainan. Parameter sangat dibutuhkan dalam sebuah permainan untuk menyelesaikan sebuah misi. Berdasarkan analisa, parameter yang digunakan disini ialah nyawa, akurasi, ketinggian, dan skor. NPC berfungsi menyerang pemain di dalam game(Kholil, 2017). Bos sebagai NPC menggunakan AI sehingga dapat menemukan pemain secara tepat dan efektif. Litertur seperti jurnal dan paper yang berkaitan dengan game dan kecerdasan buatan digunakan dalam memperkuat dan mendukung argument yang akan digunakan dalam pengembangan permainan ini(Sazaki et al., 2018). 
Implementasi Metode Path Finding dengan Penerapan Algoritma A-Star untuk Mencari Jalur Terpendek pada Game "Jumrah Launch Story"

Rancangan dibuat sebagai gambaran dalam pembuatan game ini. Perancangan antar muka game pada menu, akan terdapat beberapa tombol seperti start untuk memulai permainan, dan exit untuk keluar dari permainan. Antar muka game, menggambarkan keadaan saat pemain sudah pada posisi memulai permainan. Alur permainan pada game "Jumrah Launch Story" pemain harus mengalahkan semuah musuh atau NPC untuk bias memenangkan permainan. Cara memainkan game ini juga cukup mudah, pemain dapat menekan tombol arah untuk menentukan akan kemana karakter tersebut bergerak(kanan, kiri, space).

Metode yang akan diterapkan untuk menentukan perilaku NPC pada permainan ini adalah algortima $A$ Star. Agar game dapat berjalan seperti yang diinginkan, maka penerapan algoritma tersebut untuk metode path finding sangat diperlukan. Algoritma ini membuat total biaya lintasan menjadi seminimal mungkin(Harsadi \& Siswanti, 2019). Algoritma A-Star memerlukan dua antrian yaitu Open dan Closed. Open berisi simpul-simpul yang masih berpeluang untuk dipilih, sedangkan Closed adalah simpulsimpul yang sudah pernah digunakan dan tidak mungkin terpilih sebagai simpul terbaik(Pramono, 2015). Dalam penerapanya, akan lebih baik jika fungsi ini didefinisikan sebagai pendekatan yang sebenarnya terhadap node $n$. Nilai yang didapatkan merupakan jumlah yang diperoleh melalui sepanjang lintasan terbaik menuju simpul. Secara matematis, fungsi terhadap node $n$ ialah sebagai berikut:

$$
\begin{aligned}
& f^{\prime}(n)=g(n)+h(n) \\
& \text { dengan } \\
& f^{\prime}(n)=\text { fungsi evaluasi, } \\
& g(n)=\text { biaya yang sudah dikeluarkan dari keadaan awal } \\
& \quad \text { sampai keadaan } n, \\
& h(n)=\text { estimasi biaya untuk sampai pada suatu tujuan } \\
& \text { mulai dari n. }
\end{aligned}
$$

Gambar 1. Persamaan Matematis Fungsi Algoritma A-Star

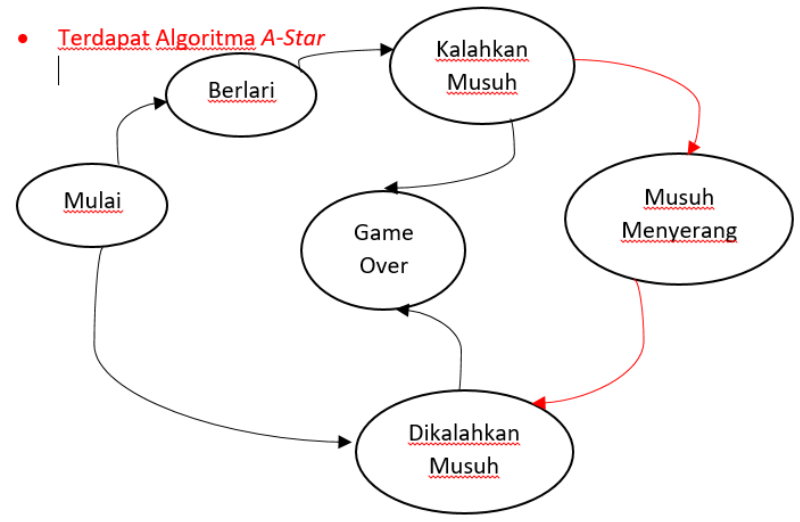

Gambar 2. Diagram A-Star Pada NPC

\section{HASIL DAN PEMBAHASAN}

Implementasi sistem ini bertujuan agar mengetahui apakah sistem yang dijalankan sesuai dengan langkah yang ditentukan untuk mengetahui apakah sistem kecerdasan yang telah menerapkan $A$ Star dapat berjalan sesuai keinginan dan dapat diimplementasikan kedalam game.

Pada Menu halaman utama dari game Jumrah Launch Story terdapat pilihan tombol play untuk mengkonfirmasi pemain untuk 
memulai permainan, dan tombol exit untuk keluar dari permainan.

Pada uji coba metode, akan dibahas pengujian dari algoritma $A$ Star yang diterapkan. Algoritma ini digunakan untuk mengatur pergerakan NPC. NPC tersebut ialah musuh sebagai NPC tanpa AI dan Bos yaitu "Jumrah" sebagai NPC dengan AI. Pengujian ini dilakukan terhadap algoritma tersebut dengan acuan perbedaan perilaku karakter yang menggunakan AI dan tidak menggunakan AI ketika game dimainkan .

Dari hasil implentasi, pergerakan NPC tanpa A-Star hanya bergerak sesuai inputan di awal, tidak akan mengejar pemain utama seperti di dunia nyata. Sedangkan pergerakan NPC menggunakan algoritma A-Star seperti nyata, menjadi lebih aktif dalam mengejar dan menyerang pemain. Jalur yang ditempuh juga menjadi lebih efisien dan NPC tetap bias mengajar pemain meskipun pemain sedang bersembunyi dan terhalang sebuah objek.

\begin{tabular}{lcc}
\hline Percobaan & NPC & NPC \\
& Tanpa AI & Dengan AI
\end{tabular}

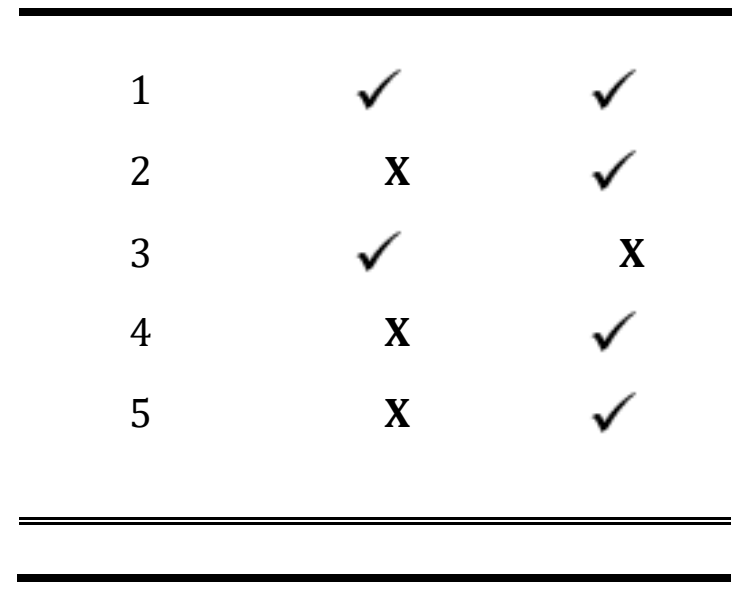

Tabel 1. Hasil Uji Coba NPC Menyerang Player

Berdasarkan Tabel 1 hasil uji coba penelitian tersebut yaitu pengaruh NPC menggunakan Ai dan tidak menggunakan AI, ketika NPC tidak menggunakan AI maka pergerakan akan tidak beraturan. Hasil uji coba tersebut menunjukkan keberhasilan menggunakan AI adalah $80 \%$ sedangkan NPC tanpa AI hanya $20 \%$.

\section{KESIMPULAN}

Perkembangan industri game saat ini membuat kita menjadi lebih tertarik saat memainkan game tersebut. Berbagai cara dikembangkan untuk menarik minat dari pemain untuk memainkan sebuah game. Salah satunya ialah mengembangkan teknologi yang ada pada game. Teknologi diterapkan agar membuat game seperti dunia nyata, salah satunya adalah kecerdasan buatan. Dari banyak teknologi yang ada, algoritma $A$-Star adalah teknologi yang digunakan dalam penelitian ini. Algoritma A-Star adalah metode dari pathfinding dimana NPC dapat mencari jalur terpendek dari rute yang akan ditempuh.

Hasil penelitian penerapan algoritma A-Star ini adalah berhasil. NPC yang menggunakan algoritma ini dapat mengejar player dan membunuh saat player kurang berhati-hati. NPC juga bias mengejar walaupun player bersembunyi dan terdapat penghalang. Sedangkan NPC tanpa algoritma A-Star hanya dapat bergerak sesuai dengan program yang telah dibuat di awal. 
Implementasi Metode Path Finding dengan Penerapan Algoritma A-Star untuk Mencari Jalur Terpendek pada Game "Jumrah Launch Story"

\section{REFERENCE}

Harsadi, P., \& Siswanti, S. (2019). Penerapan Pathfinding Menggunakan Algoritma A* Pada Non Player Character (NPC) Di Game. Jurnal Ilmiah SINUS, 17(2), 39. https://doi.org/10.30646/sinus.v17i2.423

Kholil, M. (2017). Pergerakan Pasukan Untuk Mengejar Musuh Bergerak Menggunakan D* Lite Berbasis Algoritma Pathfinding. Journal of Animation \& Games Studies, 2(1), 45. https://doi.org/10.24821/jags.v2i1.1413

Pramono, A. (2015). Algoritma Pathfinding A* Pada Game RPG Tanaman Higienis. Jurnal Edukasi Dan Penelitian Informatika (JEPIN), 1(2). https://doi.org/10.26418/jp.v1i2.12517

Prasetyo, F. R., Muh, E., Jonemaro, A., \& Akbar, M. A. (2017). Penerapan Algoritma Hybrid Pathfinding A * dan Boids untuk Game Pesawat Tempur. Jurnal Pengembangan Teknologi Informasi Dan Ilmu Komputer (J-PTIIK) Universitas Brawijaya, 1(12), 1616-1621.

Rahadiansyah, D. A., Bandung, I. T., Bandung, J. G., \& Ai, A. G. (2016). Kompleksitas Algoritma $A *$ Pada Implementasi PassiveAI Untuk Game Mobile AI.

Sazaki, Y., Satria, H., Primanita, A., \& Syahroyni, M. (2018). Analisa Perbandingan Algoritma A* dan Dynamic Pathfinding Algorithm dengan Dynamic Pathfinding Algorithm untuk NPC pada Car Racing Game. Jurnal Teknologi Informasi Dan Ilmu Komputer, 5(1), 95. https://doi.org/10.25126/jtiik.201851544

Theosaksomo, D. (2017). Pembuatan Pathfinding untuk Game Platformer dengan Memanfaatkan Library A* Karya Aron Granberg pada Unity Engine. Institut Teknologi Bandung.

Verma, S., Mehta, P., Shah, H., Shukla, S., Professor, A., Nmims, M., Sturtevant, N. R., Likhachev, M., Ferguson, D., Gordon, G., Stentz, A., \& Thrun, S. (2015). A Review on Algorithms for Pathfinding in Computer Games. IEEE Transactions on Computational Intelligence and AI in Games, March 2015, 262-271.

Wijaya, A. A., Bukhori, S., \& Oktavia, N. (2017). Perancangan dan Pembuatan Serious Game Sebagai Simulasi Aktivitas Bisnis dan Akuntansi Menggunakan Pendekatan Agent-Based Modelling. Berkala Sainstek, 5(2), 66. https://doi.org/10.19184/bst.v5i2.5532 
This page intentionally left blank. 